\title{
Diagnosis and treatment of venous thromboembolism by consultants in Scotland
}

\author{
A G PRENTICE, G D O LOWE, C D FORBES
}

\begin{abstract}
A questionnaire was sent to 508 consultants in Scotland likely to encounter deep vein thrombosis and pulmonary embolism to assess their current standard practice in diagnosis and treatment of these disorders. Replies were received from $358(70.5 \%)$. In deep vein thrombosis $47 \%$ and in pulmonary embolism $33 \%$ of consultants usually depended on clinical observation alone for diagnosis. In deep vein thrombosis $37 \%$ used venography to supplement clinical diagnosis and in pulmonary embolism $13 \%$ used angiography and $53 \%$ used isotopic scanning. Almost all consultants treated deep vein thrombosis (95\%) and pulmonary embolism (99\%) with anticoagulants. Most consultants $(81 \%)$ gave heparin by intravenous infusion. Although many consultants gave intravenous heparin for more than three days $\mathbf{( 4 9 . 5 \%}$ in deep vein thrombosis and $61 \%$ in pulmonary embolism), $25 \%$ of these consultants did not use any laboratory monitoring of heparin's effect. Large numbers of consultants gave warfarin for more than three months $(20 \%$ in deep vein thrombosis and $47 \%$ in pulmonary embolism). There was a significant tendency to give heparin $(\mathbf{p}<0.01)$ and warfarin $(\mathbf{p}<0.001)$ for longer periods in pulmonary embolism than in deep vein thrombosis. This survey shows a widely varying practice and underlines the need for further controlled studies to provide clear guidance in the management of deep vein thrombosis and pulmonary embolism.
\end{abstract}

\section{Introduction}

Despite many clinical studies of the diagnosis and treatment of deep vein thrombosis and pulmonary embolism in the past 30 years, the management of these disorders remains problematical. The problems arise mainly from the difficulties in obtaining an accurate diagnosis, and therefore also an assessment of the efficacy of treatment. Reliance on purely clinical observation for diagnosis has recently been seriously criticised in view of its inaccuracy. ${ }^{1-13}$ Frequent reports, however, of the increased

Department of Haematology, Western Infirmary, Glasgow

A G PRENTICE, MRCP, MRCPATH, senior registrar (present appointment, consultant, Department of Haematology, Plymouth General Hospital, Plymouth PL4 8QQ)

Department of Medicine, Royal Infirmary, Glasgow

G D O LOWE, MB, MRCP, lecturer

C D FORBES, MD, FRCP, senior lecturer accuracy of objective methods and their increasing availability do not necessarily mean that they are being used routinely.

Our personal experience of the management of patients with clinically suspected deep vein thrombosis and pulmonary embolism suggested pronounced variability among consultants. We thought that it would be worth while to attempt to establish by postal survey the standard practice among those consultants in Scotland who are most likely to encounter venous thromboembolism. We have tried to determine how many consultants confirm clinical diagnosis and how they treat established deep vein thrombosis and pulmonary embolism. We present an analysis of their replies to our questionnaire, and we compare their practice with published recommendations.

\section{Methods}

A questionnaire was sent to 508 consultant physicians, surgeons (including orthopaedic), and gynaecologists all practising in Scotland. The questionnaire was printed on a prepaid postcard and was designed for ease and speed of completion. Consultants were asked which methods they usually used to supplement clinical diagnosis of deep vein thrombosis and pulmonary embolism. Under deep vein thrombosis choices were none, venography, Doppler ultrasound, and ${ }^{125} \mathrm{I}-$ fibrinogen scan. Under pulmonary embolism choices were none, pulmonary angiography, lung scan, and serum fibrin degradation products. They were asked which was their usual choice of treatment in deep vein thrombosis and pulmonary embolism. Choices were none, heparin alone, warfarin alone, and heparin then warfarin. They were asked whether they gave intravenous heparin by intermittent bolus or by continuous infusion, and whether or not they monitored the dose by laboratory tests. Finally, they were asked, for both deep vein thrombosis and pulmonary embolism, how long they used heparin (choices; 0-3 days, 3-7 days, 7-10 days and $>10$ days) and warfarin (choices; 0-6 weeks, 6-12 weeks, 12-24 weeks and $>24$ weeks).

\section{Results}

Altogether $358(70.5 \%)$ completed replies were returned fit for analysis. In addition six replies were returned uncompleted for various reasons. One was sent in error to a histopathologist, two were sent in error to the same physician, and three physicians and one surgeon indicated that they did not see enough patients with deep vein thrombosis and pulmonary embolism to allow them to give meaningful answers to our questions. Although we had not asked for additional comments, some consultants gave them. The single most frequent comment concerned the meaning of the words "usual" and "usually" in our questions. More physicians (19) than surgeons (8) had conceptual difficulties with these words, but this difference did not reach statistical significance. There were no significant differences between physicians and surgeons in any other responses. Only seven consultants claimed that they lacked all investigative aids. Although we did not offer fibrinolytic therapy as a therapeutic choice, only three consultants indicated that this was a possibility dependent on the results of venography. 
TABLE I-Numbers (percentages) of consultants using investigations singly and in combinations as an aid to diagnosis

\begin{tabular}{|c|c|c|c|c|c|c|}
\hline \multicolumn{7}{|c|}{ Deep vein thrombosis } \\
\hline No investigation & Venogram & $\begin{array}{l}\text { Doppler } \\
\text { ultrasound }\end{array}$ & $\begin{array}{l}{ }^{125} \text { I-fibrinogen } \\
\text { scan }\end{array}$ & $\begin{array}{l}\text { Venogram } \\
\text { and Doppler } \\
\text { ultrasound }\end{array}$ & $\begin{array}{l}\text { Venogram and } \\
{ }^{225} \text { I-fibrinogen } \\
\text { Scan }\end{array}$ & $\begin{array}{l}\text { Doppler } \\
\text { ultrasound and } \\
{ }^{125} \text { I-fibrinogen } \\
\text { scan }\end{array}$ \\
\hline $170 *(47 \%)$ & $132 * *(37 \%)$ & $77(21.5 \%)$ & $32(9 \%)$ & $28(8 \%)$ & $16(4.5 \%)$ & $9(2 \cdot 5 \%)$ \\
\hline \multicolumn{7}{|c|}{ Pulmonary embolism } \\
\hline No investigation & $\begin{array}{l}\text { Pulmonary } \\
\text { angiography }\end{array}$ & $\begin{array}{l}\text { Isotopic } \\
\text { lung scan }\end{array}$ & $\underset{\text { FDP }}{\text { Serum }}$ & $\begin{array}{l}\text { Pulmonary } \\
\text { angiography } \\
\text { and isotopic } \\
\text { lung scan }\end{array}$ & $\begin{array}{l}\text { Pulmonary } \\
\text { angiography } \\
\text { and serum } \\
\text { FDP }\end{array}$ & $\begin{array}{c}\text { Isotopic } \\
\text { lung scan } \\
\text { and serum } \\
\text { FDP }\end{array}$ \\
\hline $119 *(33 \%)$ & $47 * *(13 \%)$ & $190(53 \%)$ & $94(26 \%)$ & $29(8 \%)$ & $5(1.5 \%)$ & $58(16 \%)$ \\
\hline
\end{tabular}

Significant differences between numbers of consultants using no investigation in deep vein thrombosis and pulmonary embolism $\left(*: \chi^{2}=15 \cdot 09 ; \mathrm{p}<0 \cdot 001\right)$ and numbers using contrast angiography in deep vein thrombosis and in pulmonary embolism $\left(* *: \chi^{2}=30 ; p<0 \cdot 001\right)$. FDP $=$ Fibrin degradation products.

\section{DIAGNOSIS}

Table I shows for both deep vein thrombosis and pulmonary embolism the numbers of consultants who chose each of the possible alternatives as aids to clinical diagnosis, with subgroups who chose combinations of investigations. Many consultants usually perform no confirmatory investigations, although significantly fewer in pulmonary embolism $(119,33 \%)$ than in deep vein thrombosis $(170,47 \%$ $\mathrm{p}<0.001)$. Venography was significantly more widely used in deep vein thrombosis $(132,37 \%)$ than was pulmonary angiography in pulmonary embolism $(47,13 \% ; \mathrm{p}<0.001)$. A third of consultants who used venography also used other investigations for deep vein thrombosis, and $72 \%$ of consultants who used pulmonary angiography also used other investigations for pulmonary embolism.

\section{TREATMENT}

Most consultants usually treated their patients with heparin followed by warfarin, $299(83.5 \%)$ in deep vein thrombosis and 333 (93\%) in pulmonary embolism. Few consultants gave no anticoagulation ( $5 \%$ in deep vein thrombosis and $1.4 \%$ in pulmonary embolism) (table II). Table III shows that significantly more consultants gave heparin $(p<0.01)$ and warfarin $(p<0.001)$ for longer periods in

TABLE II-Numbers of consultants using various choices of anticoagulant treatment

\begin{tabular}{lcccc}
\hline & $\begin{array}{c}\text { No } \\
\text { treatment }\end{array}$ & $\begin{array}{c}\text { Heparin } \\
\text { alone }\end{array}$ & $\begin{array}{c}\text { Warfarin } \\
\text { alone }\end{array}$ & $\begin{array}{c}\text { Heparin then } \\
\text { warfarin }\end{array}$ \\
\hline $\begin{array}{l}\text { Deep vein thrombosis } \\
\text { Pulmonary embolism }\end{array}$ & $\mathbf{1 8}$ & 28 & 13 & 299 \\
\hline
\end{tabular}

TABLE III-Duration of anticoagulant treatment comparing deep vein thrombosis $(D V T)$ and pulmonary embolism (PE)

\begin{tabular}{lcccccc}
\hline & & \multicolumn{2}{c}{ Heparin } & & \multicolumn{2}{c}{ Warfarin } \\
\cline { 3 - 4 } \cline { 5 - 6 } & & $>3$ days & $>7$ days & $>6$ weeks & $>12$ weeks \\
\hline No (\%) of consultants & DVT & $162(49.5)$ & $67(19)$ & $229(73)$ & $93(29)$ \\
Comparing deep vein & PE & $215(61)$ & $106(30)$ & & $285(86)$ & $156(47)$ \\
thrombosis and & $\chi^{2}$ & 9.79 & 8.14 & & 14.78 & 19.73 \\
pulmonary embolism & $\mathbf{p}$ & $<0.01$ & $<0.01$ & $<0.001$ & $<0.001$ \\
\hline
\end{tabular}

pulmonary embolism than in deep vein thrombosis. Of those consultants using heparin, 30\% (105) gave it without laboratory monitoring. More specifically it was given without laboratory monitoring in deep vein thrombosis by $22 \%$ (36) and in pulmonary embolism by $25 \%$ (54) of those giving heparin for more than three days. Most consultants $(285,81 \%)$ gave heparin by continuous intravenous infusion.

\section{Discussion}

The results of our survey show that large numbers of consultants in Scotland continue to depend on clinical observation alone in the diagnosis of deep vein thrombosis and pulmonary embolism, although greater numbers do so in deep vein thrombosis. It has been shown repeatedly, however, that only half of patients with clinically suspected deep vein thrombosis have this confirmed on ascending venography, ${ }^{1-5}$ which is widely accepted as the definitive investigation. ${ }^{6} 7$ Since most clinicians surveyed were treating deep vein thrombosis with anticoagulants $(95 \%)$ many patients in Scotland have apparently been treated with anticoagulants when thrombosis was in fact absent It has also been shown that venography followed by selective anticoagulation is significantly more cost effective than treatment on clinical grounds alone. ${ }^{8}$

Although venography is the definitive diagnostic method and is used increasingly, it can be painful, so that less invasive techniques such as ${ }^{125} \mathrm{I}$-fibrinogen scanning and Doppler ultrasound have been used as alternatives. In our study $30 \%$ of consultants used one of these two methods. Nevertheless, they are inferior in sensitivity and specificity to venography in diagnosing suspected deep vein thrombosis. ${ }^{6}$ Stepwise diagnosis with a flow chart has been recommended, using these non-invasive tests combined with each other or with venography. ${ }^{7}$ In our survey $12 \%$ of consultants were using a non-invasive technique in combination with venography, presumably as a screening test before venography.

Significantly more consultants surveyed attempted confirmation of clinical diagnosis in pulmonary embolism than in deep vein thrombosis $(67 \%$ and $53 \%, p<0.001)$. A third of consultants, however, did not attempt to confirm the clinical diagnosis of pulmonary embolism with an objective method. Since only $27-45 \%$ of patients with a clinical syndrome suggesting pulmonary embolism have this confirmed on routine pulmonary angiography, ${ }^{9-12}$ again it appears that many patients in Scotland have, been treated with anticoagulants when embolism was in fact absent.

The relative value of pulmonary angiography and lung scanning in the diagnosis of pulmonary embolism remains unclear. $^{73}$ Lung scanning (used by $53 \%$ of consultants) is non-invasive and widely available but often gives indeterminate answers. On the other hand, pulmonary angiography is definitive, but is also invasive, less widely available, and carries a significant morbidity. ${ }^{14}$ In this survey only $13 \%$ of consultants used angiography. Interestingly, over a quarter of consultants used serum fibrin degradation products as a confirmatory investigation in pulmonary embolism, despite their lack of specificity for venous thromboembolism. ${ }^{15} 16$

In both deep vein thrombosis and pulmonary embolism most consultants treated with heparin followed by warfarin, and very few gave no anticoagulants. Most consultants presumably 
believe therefore that anticoagulation is of benefit to patients with venous thromboembolism. There are no prospective, randomised, placebo-controlled trials of anticoagulants in the treatment of deep vein thrombosis. Barritt and Jordan ${ }^{17}$ suggested that anticoagulation reduced the incidence of recurrence of pulmonary embolism, whereas Johnson and Charnley ${ }^{18}$ suggested that treatment with heparin increased the incidence of recurrence. Considering these conflicting reports of efficacy, the widespread use of anticoagulants (confirmed by our survey), and the undoubted hazards in their use, ${ }^{19-21}$ further studies of placebo versus anticoagulants in the treatment of venous thromboembolism are desirable and justifiable. ${ }^{22}{ }^{23}$

A striking finding in our survey was that significantly more consultants gave heparin and warfarin for longer periods in pulmonary embolism compared with deep vein thrombosis. We are not aware of any evidence that this is necessary. The optimum duration of anticoagulation in venous thromboembolism is not well defined. Coon and Willis ${ }^{24}$ in a retrospective case control study found that patients in hospital with recurrences of venous thromboembolism had received heparin and oral anticoagulants for a shorter duration than controls. They recommended, therefore, that heparin should be given for at least 7-10 days to all patients with venous thromboembolism. On the other hand, Mant et $a l^{19}$ have associated the incidence of bleeding with the duration of heparin treatment. The 1981 edition of the British National Formulary recommends that heparin be discontinued after three days unless oral anticoagulants cannot be given. In our survey most consultants treated with heparin for under seven days, a policy which, from the available evidence, might result in more recurrences but less haemorrhage. In a prospective study of the optimum duration of oral anticoagulants ${ }^{25}$ there was no benefit from oral anticoagulants given for more than six weeks unless there was a past history of venous thromboembolism, a recurrent thrombotic tendency, or a continuing predisposing cause. In our survey, however, almost a third of consultants in deep vein thrombosis and almost a half in pulmonary embolism usually gave warfarin for more than 12 weeks. There is clearly a need for further controlled studies designed to determine the optimum duration of anticoagulant treatment in venous thromboembolism.

Most consultants surveyed gave heparin by continuous intravenous infusion rather than by intermittent injection. A review of comparative studies of these two modes of administration suggests that continuous infusion appears to be as effective as intermittent injection and is safer. ${ }^{7}$ In all reported studies continuous infusion was monitored by daily coagulation times, and there is general agreement ${ }^{726}$ that laboratory control is a worthwhile adjunct to clinical observation to prevent bleeding. The 1981 edition of the British National Formulary recommends laboratory control if heparin is continued for more than three days. In our survey, however, up to $25 \%$ of consultants giving heparin for more than three days did not perform laboratory control. Failure to monitor clotting times in patients on continuous intravenous heparin has been associated with fatal bleeding. ${ }^{21}$

We believe that this is the first survey of the diagnosis and treatment of the common and important problem of venous thromboembolism. Current practice appears to vary widely, and to be at some variance with published recommendations. Published reports, however, are often confusing, and many questions are unanswered. Further controlled studies are required to provide clearer guidance.

We thank all consultants who kindly returned our questionnaire, and Mrs Moira Hargreaves for secretarial help.

Requests for reprints to Dr A G Prentice.

\section{References}

${ }^{1}$ Haeger K. Problems of acute deep vein thrombosis. Angiology 1969; $20: 219-23$.
${ }^{2}$ Cranley JJ, Canos AJ, Sull WJ. The diagnosis of deep vein thrombosis Arch Surg 1976;111:34-6.

${ }^{3}$ Hull R, Hirsh J, Sackett DL, Powers P, Turpie AGG, Walker I. Com- ® bined use of leg scanning and impedance plethysmography in suspected $C$ venous thrombosis. $N$ Engl f Med 1977;296:1497-1500.

4 Stamatakis JD, Kakkar VV, Lawrence D, Bentley PG. The origin of thrombi in the deep veins of the lower limb: a venographic study. Br F Surg 1978;65:449-51.

5 O'Donnell TF, Abbott WM, Athanasoulis CA, Millan VG, Callow AD. \& Diagnosis of deep vein thrombosis in the outpatient by venography. Surg Gynecol Obstet 1980;150:69-74.

${ }^{6}$ Browse N. Diagnosis of deep vein thrombosis. Br Med Bull 1978;34:163-7.

7 Gallus AS. Established venous thrombosis and pulmonary embolism. जे Clin Haematol $1981 ; 10: 584-98$.

${ }^{8}$ Hull R, Hirsh J, Sackett DL, Stoddart G. Cost effectiveness of clinical diagnosis, venography and non-invasive testing in patients with symptomatic deep vein thrombosis. $N$ Engl f Med 1981;304:1561-7.

9 Dalen JE, Brooks HL, Johnson LW, Meister SG, Szucs MM, Dexter L. Pulmonary angiography in acute pulmonary embolism: indications, techniques and results in 367 patients. Am Heart $\mathcal{f} 1971 ; 81: 175-85$.

10 Bookstein JJ, Silver TM. The angiographic differential diagnosis of acute $\overrightarrow{0}$ pulmonary embolism. Radiology 1974;110:25-33.

11 Robin ED. Overdiagnosis and overtreatment of pulmonary embolism; the emperor may have no clothes. Ann Intern Med 1977;87:775-81.

12 Menzoian JO, Williams LF. Is pulmonary angiography essential or the diagnosis of acute pulmonary embolism ? Am f Surg 1979;137:543-8.

13 Kakkar VV, Sasahara AA. Diagnosis of venous thrombosis and pulmonary embolism. In: Bloom A, Thomas DP, eds. Haemostasis and thrombosis. Edinburgh: Churchill Livingstone, $1981: 662-5$.

14 Mill SR, Jackson DC, Older RA, Heaston DK, Moore AV. The incidence, etiologies, and avoidance of complications of pulmonary angiography in a large series. Radiology $1980 ; 1361: 295-9$.

15 Wood EH, Prentice CRM, McNicol GP. Association of fibrinogenfibrin-related antigen (FR antigen) with postoperative deep vein thrombosis and systemic complications. Lancet $1971 ; \mathrm{i}: 166-9$.

${ }^{16}$ Cooke ED, Gordon YB, Bowcock SA, et al. Serum fibrin (ogen) degradation products in diagnosis of deep vein thrombosis and pulmonary embolism after hip surgery. Lancet 1975;ii:51-4.

17 Barritt DW, Jordan SC. Anticoagulant drugs in the treatment of pulmonary embolism. A controlled trial. Lancet 1960;i:1309-12.

18 Johnson R, Charnley J. Treatment of pulmonary embolism in total hip replacement. Clin Orthopaed Rel Res 1977;124:149-54.

${ }^{19}$ Mant MJ, O'Brien BD, Thong KL, Hammond GW, Birtwhistle RV, Grace MG. Haemorrhagic complications of heparin therapy. Lancet $1977 ; \mathrm{i}: 1113-5$.

${ }^{20}$ Forfar JC. A seven-year analysis of haemorrhage in patients on long-term anticoagulant treatment. Br Heart $\mathcal{F}$ 1979;42:128-32.

${ }^{21}$ Lowe GDO, McKillop JH, Prentice AG. Fatal retroperitoneal haemorrhage complicating anticoagulant therapy. Postgrad Med 7 1979;55: 18-21.

${ }^{22} \mathrm{McNicol}$ GP. Conventional uses of heparin. Thrombosis et diathesis Haemorrhagica $1974 ; 33$ :97-101.

${ }^{23}$ Egermeyer P. Value of anticoagulants in the treatment of pulmonary embolism: a discussion paper. $7 R$ Soc Med $1981 ; 74: 675-81$.

${ }^{24}$ Coon WW, Willis PW. Thromboembolic complications during anticoagulant therapy. Arch Surg 1972;105:209-12.

${ }^{25}$ O'Sullivan EF. Duration of anticoagulant therapy in venous thromboembolism. Med f Aust 1972;2:1104-7.

26 Genton E, Hirsh J. Observations of anticoagulant and thrombolytic therapy in pulmonary embolism. Prog Cardiovasc Dis 1975;17:335-43.

(Accepted 8 fune 1982)

Is it wise to prescribe progesterone-only oral contraceptives to a multiparous 40-year-old woman with a history of fibroids?

There is no evidence that progestogens cause fibroids to grow: indeed, there are some unconfirmed reports of fibroids diminishing in size after progestogen treatment. ${ }^{1}$ The presence of fibroids does not decrease the efficacy of progestogen-only pills, and indeed the failure rate ought theoretically to be lower than normal among such women. The risks are not increased, but the side effect of irregular bleeding may be troublesome for this patient. By contrast, combined oral contraceptives are not usually given to women with fibroids ${ }^{2}$ because oestrogen may stimulate growth of the fibroids-though this risk has never been proved for women taking oral contraceptive pills ${ }^{1}$ and opinion is divided ${ }^{2}$ on whether fibroids contraindicate the combined pill. An intrauterine device should not be used in women with fibroids because these may distort the uterine cavity.-JAMEs OWEN DRIFE, lecturer in obstetrics and gynaecology, Bristol.

${ }^{1}$ Buttram VC, Reiter RC. Uterine leiomyomata: etiology, symptomatology, and

management. Fertil Steril $1981 ; 36: 433-5$.
2 Hawkins DF, Elder MG. Human fertility control. London: Butterworth, 1979:405. 